\title{
Corpos, medidas e nação: antropologia física na capital da República brasileira na primeira metade do século $X X$
}

Vanderlei Sebastião de Souza

Fundação Oswaldo Cruz

Ricardo Ventura Santos

Escola Nacional de Saúde Pública, Fundação Oswaldo Cruz

Em uma imagem que remete ao intenso trânsito (de ideias, práticas, pessoas e objetos) que ocorria entre as metrópoles europeias e o vasto mundo colonial no final do século XIX e início do XX, Lindee e Santos (2012, p. S8) comentaram: "A antropologia física podia ser plantada com facilidade e era também de fácil cultivo". Tal assertiva é uma referência à notável expansão e incorporação, em escala global, de arcabouços explicativos da antropologia física, o ramo da antropologia voltado para a investigação da 'história natural do gênero humano', como colocou o influente médico e anatomista francês Paul Broca em meados do século XIX. Nesse período, emanaram, sobretudo de faculdades de medicina e de museus de história natural localizados na Alemanha e França, teorias e métodos para o estudo de corpos humanos, que vieram a ser aplicados em diversas partes do mundo.

Tendo como pano de fundo a emergência do evolucionismo darwiniano a partir dos anos 1860, cabia aos antropólogos físicos, sobretudo, o estudo e a classificação das 'raças humanas' por meio de detalhadas caracterizações morfoanatômicas das várias partes do corpo. Essa minuciosa tarefa era exercitada não somente para estabelecer classificações taxonômicas (cor da pele, cor e textura do cabelo, características antropométricas, volume do cérebro, entre tantas outras), mas também para compreender como aqueles corpos haviam se constituído e, não menos, qual o futuro que lhes estava reservado. Usando uma expressão de Rose (2007), as análises realizadas pelos antropólogos físicos eram conhecimentos diretamente aplicados na definição de 'biopolíticas' ou 'políticas da vida'. Esmiuçando-se os corpos, visava-se coligir conhecimentos a serem empregados na compreensão, no monitoramento e na governança das coletividades humanas. Muitas (e prementes) eram as perguntas: quais os efeitos da miscigenação racial sobre os corpos, as mentes e as personalidades e, com isso, o que se esperar quanto ao destino de uma nação? Quais eram os 'melhores' corpos para fazer frente às novas demandas de trabalho agrícola nas colônias, sob exigentes condições ambientais e sanitárias? Quais seriam os mais 'adequados' imigrantes a serem trazidos para reverter o que se considerava ser a crescente degeneração decorrente do amálgama das raças? Como identificar, a partir de marcadores raciais, aqueles indivíduos mais propensos a comportamentos 'aberrantes', como nos casos do crime, da delinquência e da loucura?

Nas últimas duas décadas, ocorreu, em âmbito internacional, um crescente interesse por parte de historiadores e antropólogos sobre os contornos ideológicos, as dimensões teóricas e metodológicas e a construção institucional da antropologia física (Spencer, 1997; Stocking Jr., 1998; Little e Kennedy, 2010; Lindee e Santos, 2012). Uma dimensão que tem sido bastante enfatizada, com destaque para o trabalho de George Stocking Jr., diz respeito à compreensão da trajetória da antropologia, enquanto disciplina, a partir da análise histórica da antropologia física (Stocking Jr., 1968). Outra vertente, mais centrada nas entranhas da antropologia física propriamente, é a contextualização de seu desenvolvimento, levando em consideração o entorno sócio-histórico, cultural e político, em várias partes do mundo. Há muitas décadas tem havido

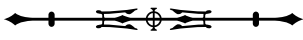


uma consistente produção acadêmica sobre a gênese e o desenvolvimento da antropologia física na Europa e América do Norte a partir do século XIX, mas não se pode dizer o mesmo acerca de outras regiões (Lindee e Santos, 2012).

No caso brasileiro, em consonância com o que ocorreu em outros países, o estabelecimento dos núcleos de investigação em antropologia física, com a consequente expansão das pesquisas e a construção de acervos, se deu a partir da segunda metade do século XIX, ainda nos tempos do Império, vindo a experimentar notável difusão nas primeiras décadas do século XX (Castro Faria, 1952; Cunha, 2002; Souza, 2011; Santos, 2012). Nesse período, em faculdades de medicina, museus de história natural, gabinetes de polícia, escolas e instituições de assistência social, a prática da antropologia física mobilizou antropólogos, médicos e naturalistas, que concentraram suas atividades no conhecimento das populações humanas, voltando suas angulares especialmente para a caracterização das populações brasileiras, sua constituição e diversidade biológica-racial. Enquadram-se nessa perspectiva as investigações antropofísicas sobre grupos indígenas, negros, sertanejos e imigrantes europeus; os debates sobre miscigenação racial, imigração e eugenia; e os estudos de biotipologia, medicina legal e antropologia jurídica.

Tomando o contexto da então capital da República, o Rio de Janeiro, nas primeiras décadas do século XX, o presente dossiê temático analisa como a antropologia física foi acionada para o conhecimento, a intervenção e a organização do 'corpo físico' da nação brasileira. Por meio de instituições como o Museu Nacional e a Faculdade de Medicina, o Rio de Janeiro se constituiu em um dos principais centros de produção e disseminação de conhecimentos em antropologia física no Brasil. Através de múltiplos e diversificados olhares sobre um contexto temporal e sociogeográfico específico, as cinco contribuições aqui publicadas dialogam com vertentes historiográficas que vêm se dedicando à análise da história da antropologia física tanto em diferentes contextos nacionais quanto em aspectos transnacionais (Stocking Jr., 1998; Penny e Bunzl, 2006; Lindee e Santos, 2012; Little e Kennedy, 2010).

No primeiro texto, intitulado "Retratos da nação: os 'tipos antropológicos' do Brasil nos estudos de Edgard Roquette-Pinto, 1910-1920", Vanderlei Sebastião de Souza analisa o amplo projeto de pesquisa mobilizado por este antropólogo para o conhecimento e a classificação dos 'tipos antropológicos' do Brasil, investigação que envolveu uma equipe de pesquisadores ligados ao Museu Nacional, entre os quais se destacaram Álvaro Fróes da Fonseca e Heloísa Alberto Torres. Conforme indica Souza, o objetivo de Roquette-Pinto era elaborar um imenso "retrato antropológico" da nação, levantando informações sobre as características anatômicas, fisiológicas e psicológicas dos diferentes 'tipos raciais' brasileiros. $O$ autor demonstra que os estudos de Roquette-Pinto dialogavam profundamente com as tradições científicas brasileiras, mas que também se reportavam à produção antropológica do exterior, especialmente da Alemanha e dos Estados Unidos. Embora Roquette-Pinto possa ser considerado o 'Franz Boas brasileiro', devido ao esforço similar que ambos fizeram para combater o racismo científico, Souza demonstra que sua antropologia dialogava muito mais com os estudos do antropólogo alemão Eugen Fischer e do geneticista norteamericano Charles Davenport. Embora ambos apresentassem, sobretudo nos anos 1920 e 1930, uma abordagem racialmente determinista, oposta àquela que o próprio Roquette-Pinto defendia, o autor do artigo argumenta que esse diálogo só foi possível devido a uma leitura seletiva e ao uso político que o antropólogo brasileiro fez da obra destes autores. Souza argumenta, ainda, que Roquette-Pinto empregou a antropologia física como uma ferramenta de expressão política, por meio da qual foi possível descrever as características raciais da população brasileira em termos positivos, enfatizando a viabilidade do país enquanto 'nação mestiça'.

Assis da Silva Gonçalves, Marcos Chor Maio e Ricardo Ventura Santos tratam, no artigo "Entre o laboratório de antropometria e a escola: a antropologia física de José Bastos de Ávila nas décadas de 1920 e 1930", das pesquisas em

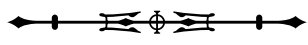


antropologia física realizadas por esse antropólogo, bem como de sua abordagem sobre a dinâmica da mestiçagem no Brasil. Os autores analisam especialmente os estudos antropométricos produzidos por Ávila sobre crianças e adolescentes de instituições escolares do Rio de Janeiro. Por meio desses estudos, conforme argumentam, o antropólogo buscava refutar a tese de que a constituição racial determinaria as capacidades de aprendizagem de crianças em idade escolar. Seguindo os trabalhos de Roquette-Pinto, Ávila defendia que os escolares poderiam atingir melhores níveis de desenvolvimento se não fossem as péssimas condições sanitárias da capital da República. Gonçalves e colaboradores também abordam as expedições cientíícas realizadas por Ávila enquanto esteve associado ao Museu Nacional, quando se envolveu em debates sobre o patrimônio arqueológico. Contextualizam, ainda, o conteúdo de um romance escrito por Ávila ("No Pacoval de Carimbe"), no qual, ao mesclar fatos, pessoas reais e conteúdos ficcionais, expressou suas concepções acerca da sociedade brasileira, abordando assuntos como educação, saúde e integração nacional. $\bigcirc$ artigo demonstra que, ao mesmo tempo em que a antropologia física praticada por Ávila era baseada em concepções fortemente racializadas, a exemplo do que ocorria com outros antropólogos da época, o resultado de seus estudos contestavam as teorias e as amarras ideológicas que viam na mestiçagem da população o principal problema do país.

O texto de Adriana Martins Keuller, intitulado "Entre antropologia e medicina: uma análise dos estudos antropológicos de Álvaro Fróes da Fonseca nas décadas de 1920 e 1930", se volta para um intelectual que transitou entre a anatomia médica e a antropologia física. Ao lado de Roquette-Pinto e Ávila, Fróes da Fonseca contribuiu para formar uma importante tradição de estudos antropológicos no Brasil, cuja característica ficou marcada por uma abordagem fortemente comprometida com os interesses nacionais. Keuller destaca o esforço de Fróes da Fonseca em defender a formação de uma antropologia que fosse, ao mesmo tempo, nacional e humanista. Ou seja, de uma ciência cuja função seria estabelecer igualdades. Este ponto de vista justificava não apenas sua proximidade com os estudos de Roquette-Pinto, de quem foi assistente no Museu Nacional, como também com a obra de Franz Boas, figura bastante citada em seus trabalhos cientíicos. A exemplo do que destaca Vanderlei de Souza em relação à obra de Roquette-Pinto, Keuller enfatiza o intenso diálogo de Fróes da Fonseca com antropólogos estrangeiros, em especial com os alemães Eugen Fischer e Ernst Rodenwaldt, cientistas que, no início do século $X X$, empreenderam importantes estudos com populações mestiças das colônias germânicas do continente africano. A autora demonstra como a antropologia física daquele país foi fundamental, por exemplo, para o estabelecimento e a padronização das atividades de campo, das técnicas e dos instrumentais utilizados pelos antropólogos do Museu Nacional. Segundo Keuller, esse trabalho de sistematização dos métodos de pesquisa antropológica foi uma das principais contribuições de Fróes da Fonseca no campo da antropologia física.

No artigo "A emergência da biotipologia no Brasil: medir e classificar a morfologia, a fisiologia e o temperamento do brasileiro na década de 1930", Ana Carolina Vimieiro Gomes aborda como a antropologia física foi empregada pela biotipologia, uma ciência emergente no Brasil naquele período. A autora destaca especialmente os estudos empreendidos na Faculdade de Medicina do Rio de Janeiro, tendo como principais autores os médicos Waldemar Berardinelli e Isaac Brown. Em diálogo com a tradição italiana de Nicole Pende, Giacinto Viola e Mario Barbàra, mas também com a antropologia do Museu Nacional, a biotipologia brasileira foi acionada para medir e classificar a população de diferentes maneiras, determinando o temperamento, o 'tipo' corporal ou o 'normotipo do homem médio brasileiro', conforme definição de Brown, cuja obra é cuidadosamente analisada por Gomes. De acordo com a autora, a emergência da biotipologia na capital da República ocorreu num período de intenso debate político sobre a formação da nacionalidade brasileira. Vale lembrar que as décadas de 1920 e 1930 foram marcadas por amplas discussões em torno das ideias eugênicas, do controle e da seleção dos imigrantes, e da escolha de qual seria, do ponto de vista antropológico, o

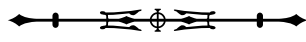


representante ideal do 'homem brasileiro'. Reinava o embate entre antropólogos e biotipologistas sobre como determinar a classificação dos 'tipos antropológicos' do Brasil diante da extrema heterogeneidade racial do país. A autora analisa, inclusive, o modo como Brown e outros biotipologistas lidaram com as classificações e os debates promovidos por Roquette-Pinto, Arthur Lobo e Oliveira Viana acerca dos 'tipos raciais' brasileiros.

Diego Galeano, em "Identidade cifrada no corpo: o bertillonnage e o Gabinete Antropométrico na Polícia do Rio de Janeiro, 1894-1903", aborda a história da antropometria judiciária e o uso do bertillonnage no Brasil na passagem do século XIX para o XX. Em diálogo com uma ampla historiografia, o autor destaca, num primeiro momento, o contexto de emergência do método antropométrico desenvolvido na França por Alphonse Bertillon, que consistia na descrição morfológica e fisionômica das pessoas, o chamado 'retrato falado'. Este método foi criado, sob inspiração da antropologia física de Paul Broca e Adolphe Quételet, para auxiliar no processo de investigação e identificação criminal, empregando a ciência para a resolução de problemas concretos das burocracias judiciais e policiais. Disseminado a partir do final do século XIX, conforme destaca o autor, o bertillonnage foi rapidamente adotado em diferentes países, com forte adesão na América Latina. O método encontrou um expressivo número de entusiastas no Brasil, sendo bem aceito pelas elites, que viam na antropologia judiciária a aplicação de fundamentos científicos e a possibilidade de modernização do poder judiciário e policial do país. Contudo, conforme explica Galeano, a história da recepção desse método é polêmica, seja no Brasil ou no exterior, uma vez que encontrou resistência dos adeptos da datiloscopia, sistema que se consagraria no início do século $X X$. Embora tenha sobrevivido por poucos anos, a antropometria judiciária, conforme argumenta Galeano, é um objeto importante não apenas para compreender a aplicação da ciência na prática policial, como também para problematizar os processos de recepção, tradução e adaptação envolvidos na aplicação da antropometria no período.

Na seção "Memória" deste número, publicamos "O Congresso Universal de Raças, Londres, 1911: contextos, temas e debates", no qual destacamos a participação dos antropólogos João Baptista de Lacerda e Edgard RoquettePinto, enviados pelo governo de Hermes da Fonseca como delegados do Brasil, no primeiro Congresso Universal de Raças, realizado em Londres, em 1911. O texto tem como foco o contorno histórico e político no qual se inseriu o evento, marcado pelo imperialismo europeu e pelas relações conflituosas envolvendo as principais nações europeias e suas colônias na África e na Ásia. Analisamos também os principais temas abordados no evento por antropólogos, sociólogos e ativistas sociais de diferentes lugares do mundo, especialmente o debate sobre raça e mestiçagem, no qual os antropólogos brasileiros estiveram diretamente envolvidos.

Como nos lembra o historiador da antropologia Claude Blanckaert (2001, p. 145), por meio da antropometria, largamente empregada pela antropologia física na primeira metade do século $X X$, conforme evidenciam os textos desse dossiê, almejava-se "esclarecer o lugar biológico do homem na natureza e delimitar a particularidade de suas raças (...), situar o homem entre as espécies vivas, e sobretudo de classificar os povos, de distribuí-los por grupos diferenciados, segundo princípios objetivistas e hierárquicos". Nessa linha, os trabalhos publicados neste dossiê traçam um detalhado panorama dos esforços empreendidos, por meio da antropologia física, para identificar o lugar, para classificar e distribuir os corpos dos brasileiros em uma série de contextos institucionais da capital da República, o Rio de Janeiro. Nas análises empreendidas pelos autores, ficam evidentes as imbricações entre a prática da antropologia física e as questões sociopolíticas que mobilizavam a sociedade brasileira no início do século $X X$, sobretudo no que dizia respeito à organização do país, ao conhecimento de sua população e às discussões sobre a formação da nacionalidade brasileira. No plano transnacional, os trabalhos trazem à tona as íntimas relações que ligavam a antropologia física no Brasil e aquela que vinha sendo produzida desde o final do século XIX em países como a França, a Alemanha e os

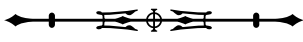


Estados Unidos. Expande-se, assim, tomando a antropologia física como foco de análise, a compreensão historiográfica em torno das redes internacionais em que estiveram envolvidos os intelectuais brasileiros, bem como da própria circulação do conhecimento científico para além das fronteiras nacionais.

\section{AGRADECIMENTOS}

Nossos agradecimentos ao Dr. Nelson Sanjad, editor do "Boletim do Museu Paraense Emílio Goeldi. Ciências Humanas", e sua equipe. Como organizadores, seria difícil imaginar trabalhar com uma equipe mais eficiente e prestativa. Agradecemos também a todos os autores pelo interesse em participar nesse projeto editorial. Também ao Conselho Nacional de Desenvolvimento Científico e Tecnológico (CNPq), pela concessão de Bolsa de Pós-Doutorado Júnior a Vanderlei Sebastião de Souza (processo n 161671/2011-0) e de Bolsa de Produtividade em Pesquisa a Ricardo Ventura Santos.

\section{REFERÊNCIAS}

BLANCKAERT, Claude. Lógicas da antropotecnia: mensuração do homem e bio-sociologia (1860-1920). Revista Brasileira de História, v. 21, n. 41, p. 145-156, 2001.

CASTRO FARIA, Luiz de. Pesquisas de Antropologia Física no Brasil. Boletim do Museu Nacional, Nova Série, Antropologia, n. 13, p. 1-106, 1952.

CUNHA, Olívia M. G. Intenção e gesto: pessoa, cor e a produção cotidiana da (in)diferença no Rio de Janeiro (1927-1942). Rio de Janeiro: Arquivo Nacional, 2002.

LINDEE, Susan; SANTOS, Ricardo Ventura. The biological anthropology of living human populations: world histories, national styles and international networks. Current Anthropology, v. 53, p. S3-S16, 2012.

LITTLE, Michael; KENNEDY, Kenneth (Orgs.). Histories of American physical anthropology in the twentieth century. Lanham: Lexington Books, 2010.

PENNY, H. Glenn; BUNZL, Matti (Orgs.). Worldly provincialism: German anthropology in the Age of Empire. Ann Arbor: University of Michigan Press, 2006.

ROSE, Nikolas. The politics of life itself: biomedicine, power and subjectivity in the twenty-first century. Princeton: Princeton University Press, 2007.

SANTOS, Ricardo Ventura. Guardian angel on a nation's path: contexts and trajectories of physical anthropology in Brazil in the late nineteenth and early twentieth centuries. Current Anthropology, v. 53, p. S17-S32, 2012.

SOUZA, Vanderlei Sebastião de. Em busca do Brasil: Edgard Roquette-Pinto e o retrato antropológico brasileiro (1905-1935). 2011. 382 f. Tese (Doutorado em História) - Casa de Oswaldo Cruz, Fundação Oswaldo Cruz, Rio de Janeiro, 2011.

SPENCER, Frank (Org.). History of physical anthropology: an encyclopedia. New York: Garland Publishing, 1997.

STOCKING JR., George (Ed.). Bones, bodies, behavior: essays on biological anthropology. Madison, Wisconsin: The University of Wisconsin Press, 1998.

STOCKING JR., George. Race, culture, and evolution: essays in the history of anthropology. New York: Free Press, 1968.

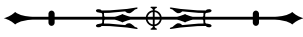


